\title{
Root Surface Treatment of Avulsed Teeth-A Review
}

\author{
Malini V* \\ Department of Preventive and Pediatric Dentistry, Kerala University of Health Sciences, India
}

*Corresponding author: Malini Venugopal, Department of Preventive and Pediatric Dentistry, Kerala University of Health Sciences, Kerala, India, Email: mailtomalu85@gmail.com

\section{Review Article \\ Volume 5 Issue 2}

Received Date: April 04, 2020

Published Date: May 01, 2020

DOI: $10.23880 /$ oajds- 16000250

\section{Abstract}

The chances of root surface damage are higher when tooth replantation is not performed immediately or if the avulsed tooth is not stored in an adequate medium. This invariably leads to necrosis of pulp tissue, periodontal ligament cells and cementum, thus increasing the possibility of root resorption, which is the main cause of loss of replanted teeth. This paper presents a comprehensive on material used for root surface treatments to remove necrotic cemental periodontal ligament thus improving the prognosis of avulsed teeth.

Keywords: Avulsed teeth; Periodontal ligament; Tooth replantation; Necrotic cemental; Cementum layer

\section{Introduction}

One of the greatest concerns in tooth replantation has been the understanding of the mechanisms that rule healing process because if these mechanisms are better controlled, the organism might have better conditions to promote repair of the injured tissues. However, a great deal of difficulty is involved because tooth-supporting tissues are composed of a wide variety of cell types with different roles, characteristics and behaviors.

The presence of necrotic periodontal ligament remnants stimulates the occurrence of external root resorption, which is the major cause of loss of replanted teeth. It has been shown that chemical or mechanical removal or treatment of the necrotic cemental periodontal ligament leads to the occurrence of more areas of ankylosis rather than replacement resorption. Several substances have been used for the treatment of the root surface of replanted teeth in an attempt to increase their retention rate [1].

\section{Mechanical Methods}

One of the steps of the root surface treatment is the removal of necrotic periodontal ligament. This can be performed either mechanically by scraping with curettes, scalpel blade, rubber cup polishing with pumice/water slurry, diamond bur and sandpaper disk or chemically with sodium hypochlorite. Robinson bristle brush with pumice has been assessed under scanning electron microscopy. The quantitative and qualitative analyses of the results showed that both techniques were effective and preserved the cementum layer. The mechanical method has the additional advantages of not damaging the tissues, being rapid and easy to perform. Other studies evaluated several substances for root surface treatment without removing the necrotic periodontal ligament and found similar results, i.e. ankyloses and replacement resorption $[2,3]$.

\section{Chemical Methods}

\section{Sodium Hypochlorite}

As regards the removal of necrotic root periodontal ligament, the authors who employed the chemical removal with sodium hypochlorite justify its use because this technique preserves the cemental layer, which is an important barrier against the external root resorption. In spite of being an excellent organic material solvent and efficient agent for the removal of periodontal ligament remnants, sodium hypochlorite is considered to be toxic for the supporting periodontal tissues. Sodium hypochlorite, particularly at high concentrations, may possibly lead to the formation of a connective tissue that does not reattach to the tooth surface. 


\section{Open Access Journal of Dental Sciences}

\section{Fluorides}

Several authors have recommended the use of fluoride solutions in different forms and concentrations to treat the root surface in cases of delayed tooth replantation, assuming that the demineralized dentin surface would be more prone to fluoride incorporation and might become more resistant to resorption. Among the fluoride solutions, the use of $2 \%$ acidulated sodium phosphate fluoride has shown a decrease in inflammatory root resorption and the predominance of areas of ankylosis and replacement resorption. Fluoride probably acts directly on the bone tissue, cementum and dentin, by converting hydroxyapatite into fluoroapatite, or by a specific inhibitory action on the clastic cells, or even an association of both hypotheses. Another property of fluoride is its ability to inhibit microbial growth and metabolism, decreasing cell ph. Some authors used neutral sodium fluoride and did not find any difference in repair compared with acidulated sodium fluoride.

Studies have also investigated the use of $1 \%$ and $10 \%$ stannous fluoride and reported that the concentration of $10 \%$ was more deleterious to the periodontal ligament, pulp and alveolar bone, whereas the use of $1 \%$ stannous fluoride yielded better results, with fewer areas of external root resorption. Disadvantages of these solutions are the possibility of tooth crown staining, environmental instability and connective tissue irritation.

\section{Hydrochloric Acid}

Hydrochloric acid has also been used in association with an enzyme, hyaluronidase, with the aim of decalcifying the cementum without denaturing the collagen matrix and has been shown to decrease root resorption significantly. Nordenram A, et al. [3] evaluated the use of hydrochloric acid alone but did not have favorable results. Phosphoric acid at $50 \%$ has been used for the same purpose, and the results revealed that its use alone increased the occurrence of root resorption. The findings of a previous study showed that the use of $40 \%$ formol to treat root surfaces of replanted and transplanted dogs' teeth led to rapid and complete root destruction within 6 months, with no periodontal ligament regeneration [4].

\section{Citric Acid}

In an attempt to expose collagen fibers on root cementum and promote a contact surface for reattachment of periodontal ligament collagen fibers, some authors have proposed the treatment of root surface with citric acid and observed a large number of areas of ankylosis and replacement resorption. Ripamonti U and Petit JC, after demineralizing the root surface with citric acid, used a concentrate of allogenic fibronectin-fibrin with the aim of preventing ankylosis but did not succeed [4].

\section{Auto Transplantation}

Andreasen JO and Kristerson L [5] investigated the auto transplantation of connective tissue, such as that found in the fascial sheath or subcutaneous, mucosal and periosteal tissues, for potential replacement of the periodontal ligament. The results showed that this procedure was unable of both completely preventing ankylosis and forming new cementum. Only tissues of odontogenic origin, such as periodontal ligament, tooth follicle and gingival connective tissue, have such ability $[5,6]$.

\section{Calcium Hydroxide}

The use of a calcium hydroxide saturated solution for the treatment of root surface produced replacement resorption and ankylosis. Isolan and Carvalho tested the buffered alkaline solution and had similar results.

\section{Antibiotics}

The findings of previous studies showed that the treatment of root surface with the antibiotic rifacin M (75 $\mathrm{mg}$ ) prevented inflammatory resorption from the $10^{\text {th }}$ to $60^{\text {th }}$ post replantation day, but was not able to prevent the occurrence of replacement resorption and dentoalveolar ankylosis. The action of tetracycline on microorganisms that contaminate the root surface during the extra-alveolar period has also been investigated. Although it had no effect on the microorganisms present in the necrotic pulp tissue, tetracycline reduced the occurrence of ankylosis and inflammatory resorption. Minocycline, a tetracyclinederived antibiotic, has also been investigated, but its use for root surface treatment is not recommended because of its inability to prevent or attenuate external root resorption.

The use of a commercially prepared antibioticcorticosteroid product has been evaluated for root surface treatment. It was shown to reduce inflammation when applied topically for a short time, but induced an intense inflammatory reaction when maintained in contact for a longer period, thus compromising the periapical healing. Sae-Lim V, et al. assessed the topical effect of dexamethasone and its systemic association in cases of tooth replantation and concluded that topical use improves the repair, but it does not avoid the occurrence of replacement resorption [6].

Alendronate, a substance capable of inhibiting osteoclastic activity, has also been employed for root surface treatment before replantation of avulsed teeth in order to prevent the occurrence of inflammatory resorption. The results revealed a decrease in the resorption process but not 
in the occurrence of ankylosis [7].

\section{Vitamin C}

Taking into account the characteristics of vitamin C, mainly its role in collagen synthesis and its acid ph. Panzarini, et al. evaluated the use of vitamin C for the treatment of root surface in cases of delayed replantation, aiming at providing a longer survival for replanted teeth. The results were similar to those obtained with $2 \%$ acidulate sodium phosphate fluoride, with areas of replacement resorption and ankylosis [7].

Mori GG and Garcia RB [8] used acetazolamide for root surface treatment in an attempt to minimize the occurrence of root resorption in the replanted teeth. This substance inhibits the carbonic anhydrase enzyme that is responsible for maintaining the $\mathrm{pH}$ acid within the resorption area, which is essential for the action of most enzymes involved in the resorption process. Because of the presence of hydrogen ions, the $\mathrm{pH}$ in the resorption zone drops to around 4.7. The formation of hydrogen ions, in turn, depends on carbon dioxide gas hydration. As this reaction is catalyzed by the carbonic anhydrase enzyme, the absence or inhibition of this enzyme alters the resorption cycle and ends up limiting resorption. However, in the aforementioned study, acetazolamide was not capable of preventing the occurrence of ankylosis and inflammatory and replacement resorptions [9].

\section{Emdogain}

The use of Emdogain, which is an enamel matrix derivative, has been studied, based on the hypothesis that the development of acellular cementum would be preceded by a period of protein secretion related to the enamel and that the key for re-establishing a functional periodontal ligament is the formation of acellular cementum. Gestrelius $S$, et al. [9] investigated the influence of Emdogain on the properties of periodontal ligament cells, such as migration, adhesiveness, proliferation, biosynthetic activity and nodule formation. They found that although this substance increased the proliferation of periodontal ligament cells and protein synthesis, as well as the formation of nodules, it had no significant effect on the migration and adhesiveness of these cells. Other studies using Emdogain in delayed tooth replantation found that it was unable to prevent or heal ankylosis after tooth replantation [10].

\section{Propolis}

Propolis is a resinous substance derived from tree exudates mixed with floral sap, salivary bee secretions,wax, and pollen. Polyphenols have been identified as the main organic constituents of propolis, mainly represented by flavonoids and accompanied by phenolic acids, esters, phenolic aldehydes, and ketones. Various studies suggest that the antimicrobial, anti-inflammatory, and antioxidant properties of propolis may contribute to PDL repair of replanted teeth and propolis can act as good afrnt for surface treatment of avulsed tooth [10-12].

\section{Conclusion}

The success of replantation depends on a number of factors that may contribute to accelerate or minimize the occurrence of root resorption or ankylosis. The surface treatment of root surface of avulsed tooth is one among the important determinant factor which improves its prognosis. Surface treatment not only helps in removing necrotic tissues but also help in maintaining the vitality of the healthy periodontal ligament cells that remain on root surface.

\section{References}

1. Okamoto T, Hanada E, SaadNeto M (1986) Reimplantation of incisor teeth of rats: the importance of nonvital cementum periodontal ligament. Rev Odontol UNESP 16: 53-64.

2. Lindskog S, Pierce AM, Blomlof L, Hammarstrom L (1985) The role of the necrotic periodontal membrane in cementum resorption and ankylosis. Endod Dent Traumatol 1(3): 96-101.

3. Nordenram A, Bang G, Anneroth G (1973) A histopathologic study of replanted teeth with superficially demineralized root surfaces in Java monkeys. Scand J Dent Res 81(4): 294-302.

4. Ripamonti U, Petit JC (1989) Patterns of healing on replanted baboon incisiors coated with an allogeneic fibrin-fibronectin protein concentrate. J Periodontal Res 24(5): 335-342.

5. Andreasen JO, Kristerson L (1981) Evaluation of different types of autotransplanted connective tissues as potential periodontal ligament substitutes. An experimental replantation study in monkeys. Int J Oral Surg 10(3): 189-201.

6. Sae Lim V, Metzger Z, Trope M (1998) Local dexamethasone improves periodontal healing of replanted dog's teeth. Endod Dent Traumatol 14(5): 232-236.

7. Panzarini SR, Perri de Carvalho AC, Poi WR, Sonoda CK (2005) Use of vitamin $C$ in delayed tooth replantation. Braz Dent J 16(1): 17-22.

8. Mori GG, Garcia RB (2002) Microscopic study of the 
Open Access Journal of Dental Sciences

effect of root surface treatment with acetazolamide in avulsed and reimplanted rat teeth. Rev Fac Odontol Bauru 10: 180-185.

9. Gestrelius S, Andersson C, Lidstrom D, Hammarstrom L, Somerman M (1997) In vitro studies on periodontal ligament cells and enamel matrix derivative. J Clin Periodontol 24: 685-692.

10. Lee YJ, Vann WF (2001) Management of avulsed permanent incisors: A decision analysis based on changing concept. Pediatric Dent 23: 3-6.

11. Martin MP, Pileggi R (2004) A Quantitative analysis of Propolis: a promising new storage media following avulsion. Endod Dent Traumatol 20(2): 80-85.

12. Casaroto AR, Hidalgo MM, Sell AM, Franco SL, Cuman RKN, et al. (2010) Study of the effectiveness of propolis extract as a storage medium for avulsed teeth. Dent Traumatol 26(4): 323-331. 